\title{
Characteristics and Mechanism of Low Temperature Dehydrochlorination of Poly(vinyl chloride) in the Presence of Zinc(II) Oxide
}

Takashi KOSUDA, Tomohiko OKADA, Shogo NOZAKA, Yukitaka MATSUZAWA, Takuya SHIMIZU, Senji HAMANAKA and Shozi MISHIMA *

Department of Chemistry and Material Engineering, Faculty of Engineering, Shinshu University, Wakasato 4-17-1, Nagano 380-8553, JAPAN

mailto: smisima@shinshu-u.ac.jp

* To whom all correspondence should be addressed.

Phone : +81-26-269-5406, Fax : +81-26-269-5424

\begin{abstract}
Characteristics of low temperature (473 K) dehydrochlorination of PVC powder in the presence of $\mathrm{ZnO}$ were studied in nitrogen flow and a reaction mechanism was proposed. It was revealed that a large portion of chlorine (ca. 70 \%) in PVC powder reacts with $\mathrm{ZnO}$ accompanying evolution of water and a slight amount of $\mathrm{HCl}$ (ca. $0.5 \%$ ) without any organic gas. Analysis of the solid product by SEM, XRD and IR suggested that an apparent solid-solid reaction proceeds at $473 \mathrm{~K}$ via formation of a liquid phase which acts as reaction promoter and that the solid product is abundant in aliphatic $(\mathrm{CH})_{\mathrm{n}}$ polymer. It was concluded that the first step of the dehydrochlorination is cross-linking C-C single bond formation in a polymer chain or among polymer chains followed by isomerization to polyene and aromatics.
\end{abstract}

Key Words : Poly(vinyl chloride), Dehydrochlorination, Zinc(II) oxide, Cross-linking Running title : low temperature dehydrochlorination of PVC by ZnO

\section{Introduction}

A large amount of poly(vinyl chloride) (abbreviated as PVC, hereinafter) has been produced and used as a useful material because of its excellent electrical, mechanical 
and chemical properties. As a result, vast amounts of waste PVC and waste plastic mixtures containing PVC have been produced. Although a part of them have been reused as textiles, reformed containers, etc., major parts of the waste PVC have been buried under the ground because incineration of PVC generates a large quantity of corrosive $\mathrm{HCl}$ gas and harmful organic compounds including organochlorines such as dioxin. In recent years, establishment of environmentally benign recycling processes for the waste PVC becomes an urgent subject.

There have been many studies for thermal decomposition of PVC. It is widely accepted that the first step of thermal decomposition of PVC is polyene formation accompanying evolution of a large quantity of $\mathrm{HCl}$ gas [1-6]. The polyene once formed easily turns to aromatic compounds such as benzene and toluene via C-C bond cleavage. Thermal decomposition of PVC in the presence of various metal oxides and metal chlorides have also been studied [7-17] and revealed that metal oxides such as $\mathrm{ZnO}$ [9,12], iron oxide [14] and zinc(II) chloride [16] accelerate decomposition of PVC to aromatic compounds. Zhang et al. [12] reported based on thermogravimetric-mass spectrometry that $\mathrm{ZnO}$ reacts directly with PVC at $473 \mathrm{~K}$, a lower temperature than that of thermal decomposition ( $>523 \mathrm{~K}$ ) of pure PVC, and the only volatile product is water. Their results are worth noting because dehydrochlorination of PVC in the presence of $\mathrm{ZnO}$ proceeds without production of volatile organic compounds. However, characteristics and mechanism of the low temperature dehydrochlorination in the presence of $\mathrm{ZnO}$ have not been clarified yet. Since one of desirable recycling processes of waste PVC is conversion of PVC to harmless materials without producing any harmful volatile compounds, the low temperature dehydrochlorination is of great promise as a new method for environmentally benign recycling of waste PVC. In the present study, we studied characteristics and reaction mechanism of the low temperature dehydrochlorination of PVC in the presence of $\mathrm{ZnO}$.

\section{Experimental}

\subsection{Materials}

PVC powder (polymerization degree $=1100$, particle size $=50-150 \mu \mathrm{m}), \mathrm{ZnO}$ and $\mathrm{Ca}(\mathrm{OH})_{2}$ were guaranteed reagents purchased from Wako Pure Chemical Industries, Co., Ltd., and used as purchased. $\mathrm{CaO}$ was prepared by heating $\mathrm{Ca}(\mathrm{OH})_{2}$ at $1173 \mathrm{~K}$ for 
$4 \mathrm{~h}$ in air.

\subsection{Thermal analysis}

The mixture of PVC and $\mathrm{ZnO}$ of molar ratio 1.0:0.75 (expressed as PVC(1.0)-ZnO(0.75), hereinafter) was mixed thoroughly in an agate mortar before use, where the molecule of PVC was regarded formally as $\mathrm{C}_{2} \mathrm{H}_{3} \mathrm{Cl}$ for the calculation of molar ratio. Similarly, PVC(1.0)-CaO(1.25) was also mixed thoroughly before use. Thermal analysis were carried out by Shimadzu DTA-50 in nitrogen flow $\left(2.0 \times 10^{-2}\right.$ $\mathrm{dm}^{3} \min ^{-1}$ ) at the heating rate $10 \mathrm{~K} \mathrm{~min}^{-1}$ using $\alpha-\mathrm{Al}_{2} \mathrm{O}_{3}$ as the standard material.

\subsection{Dehydrochlorination of $\mathrm{PVC}$ by $\mathrm{ZnO}$}

PVC (1.0)-ZnO (0.75) was prepared by mixing $1.0 \mathrm{~g}$ PVC and $1.0 \mathrm{~g} \mathrm{ZnO}$ in an alumina mortar. Similarly, mixtures of PVC and $\mathrm{ZnO}$ of different molar ratio, PVC (1.0)-ZnO (0.75-3.0), were prepared. Each of mixtures was transferred to $5.0 \times 10^{-2} \mathrm{dm}^{3}$ glass reactor equipped with two gas flow tubes and heated at a temperature between 453-673 $\mathrm{K}$ for $0.5-5 \mathrm{~h}$ in nitrogen flow $\left(6.0 \times 10^{-2} \mathrm{dm}^{3} \mathrm{~min}^{-1}\right)$. A preliminary study showed that the reaction completes explosively and generates large amounts of heat and water vapor, so that dehydrochlorination reactions were carried out by spreading the sample powder as thin layer at the bottom of the glass reactor to avoid rise in temperature. Even in such condition, the reaction completed momentarily. Gaseous $\mathrm{HCl}$ evolved during the thermal treatment was trapped in $1.0 \mathrm{~mol} \mathrm{dm}^{-3} \mathrm{NaOH}$ aqueous solution and titrated with $1.0 \mathrm{~mol} \mathrm{dm}^{-3} \mathrm{HCl}$. The solid product was washed thoroughly with $1.0 \mathrm{~mol} \mathrm{dm}{ }^{-3}$ nitric acid to dissolve out zinc compounds such as $\mathrm{ZnCl}_{2}$ and $\mathrm{ZnO}$. The amount of chlorine in the washings was measured by Mohr method to estimate the amount of chlorine removed from PVC. A known amount of the solid product was burned thoroughly in a quartz glass column at $873 \mathrm{~K}$ in air flow and resulting chlorine compounds were collected in $1.0 \mathrm{~mol} \mathrm{dm}^{-3} \mathrm{NaOH}$ solution and titrated by Mohr method to estimate the amount of chlorine remaining in the dehydrochlorinated PVC. Temperature programmed decomposition of PVC-ZnO mixture was carried out at the heating rate $1.4 \mathrm{~K} \mathrm{~min}^{-1}$ under nitrogen flow $\left(3.0 \times 10^{-2} \mathrm{dm}^{3} \mathrm{~min}^{-1}\right.$ ) by using a flow reactor equipped with a gas chromatograph (Shimadzu GC-8A equipped with 
PEG-6000 packed in $2 \mathrm{~m}$ glass column and FID detector) and evolved gas was analyzed.

\subsection{Microscopic observation}

The shape of PVC, PVC-ZnO and dehydrochlorinated PVC were observed by using Hitachi Scanning Electron Microscope S-4100.

\section{5. $X R D$ and FT-IR}

XRD patterns were obtained by using Rigaku RINT 2200V/PC diffractometer (monochromatic $\mathrm{Cu} \mathrm{K}_{\alpha}$ ) operated at $20 \mathrm{~mA}, 40 \mathrm{kV}$. FT-IR spectra were recorded using JASCO FT-IR 4200 spectrophotometer by applying $\mathrm{KBr}$ pelletizing method.

\section{Results and discussion}

\subsection{Thermal analysis}

TG and DTA curves of PVC(1.0)-ZnO(0.75) and PVC(1.0)-CaO(1.25) are shown in Fig. 1 together with those of pure PVC. As shown in Fig. 1(A), the mass loss of pure PVC initiates at around $523 \mathrm{~K}$ and proceeds in the range 523-623 K. As shown in Fig. 1(B), the mass loss of PVC gives an endothermic peak at around $560 \mathrm{~K}$. These results show that endothermic dehydrochlorination of pure PVC proceeds above $523 \mathrm{~K}$ in qualitatively agreement with literature data [11]. In the case of PVC-CaO, the mass loss proceeds at the same temperature range as that of pure PVC except for smaller mass loss because of production of non-volatile $\mathrm{CaCl}_{2}$ instead of $\mathrm{HCl}$. The mass loss accompanies an intense exothermic peak at around $573 \mathrm{~K}$. Because the temperature of the exothermic peak is higher than that of dehydrochlorination of pure PVC, this peak is ascribed to exothermic reaction of $\mathrm{CaO}$ and $\mathrm{HCl}$ gas produced from $\mathrm{PVC}$.

\section{(Insert Fig. 1)}

As shown by curve (c) in Fig. 1(A), the mass loss of ZnO-PVC begins around $473 \mathrm{~K}$, a lower temperature than that of pure PVC and PVC-CaO and the mass loss is 
exothermic as shown curve (c) in Fig. 1(B). Since evolution of $\mathrm{HCl}$ gas from pure PVC needs temperatures more than $523 \mathrm{~K}$, the exothermic mass loss observed here is ascribed to the direct reaction between PVC and ZnO. Zhang et al. [12] reported based on thermogravimetric-mass spectrometry that $\mathrm{ZnO}$ reacts directly with PVC giving only water and $\mathrm{ZnCl}_{2}$ at $473-555 \mathrm{~K}$ and evolution of volatile organic compounds requires a higher temperature than $555 \mathrm{~K}$. Since the results obtained here are in accordance with those of Zhang et al., it is concluded that PVC react directly with $\mathrm{ZnO}$ at around $473 \mathrm{~K}$ without formation of $\mathrm{HCl}$ gas.

\subsection{Dehydrochlorination of PVC-ZnO mixtures}

Representative results of thermal dehydrochlorination of PVC-ZnO mixtures at 473 $\mathrm{K}$ in nitrogen flow are summarized in Table 1 . Since $0.5 \mathrm{~mol}$ of $\mathrm{ZnO}$ is required stoichiometrically for the complete dehydrochlorination of $1.0 \mathrm{~mol}$ PVC, excess amounts of $\mathrm{ZnO}$ ( 2 or 6 times) exist in all of the mixtures shown in Table 1. Results of run 1 in the table show that the amounts of chlorine evolved as $\mathrm{HCl}$ gas were only $0.5 \%$ in molar scale. The amounts of chlorine remaining in dehydrochlorinated PVC were $30 \%$ and the amounts of chlorine removed from PVC as soluble zinc salt were $67 \%$. Similar results were obtained in other runs as shown in the table independent of molar ratio of mixtures and reaction time. These results suggest that the reaction proceeds rapidly and the direct reaction produces water, Zn-salts of chlorine and a slight amount of $\mathrm{HCl}$.

\section{(Insert Table 1)}

For all runs shown in the table, sample mixture of white fine powder turned black powder after reaction, suggesting that PVC did not melt during the reaction. On the other hand, since the melting point of $\mathrm{ZnO}$ is far higher than $473 \mathrm{~K}$, the reaction is, at least seemingly, a solid-solid reaction between two solid, PVC and $\mathrm{ZnO}$. It is queer at the first face that considerable amount of chlorine (ca. 70\%) in PVC can react with $\mathrm{ZnO}$ in spite of solid-solid reaction. These results imply that $\mathrm{ZnO}$ becomes mobile by dissolved in a liquid phase formed during the reaction and penetrates into PVC particles. 
Hence the dehydrochlorination of PVC can be regarded as a seemingly solid-solid reaction accompanying formation of a liquid phase during reaction.

As shown in the table, temperature programmed decomposition of PVC-ZnO mixtures showed that no volatile organic compounds is evolved at around $493 \mathrm{~K}$. This result is in qualitatively agreement with those reported by Zhang et al. [12] based on thermogravimetric-mass spectroscopy. It has been widely accepted that the first step of dehydrochlorination of PVC is polyene formation followed by formation of aromatic compounds such as benzene, as described above. If the reaction of PVC-ZnO mixtures proceeds via polyene formation, at least small amounts of organic compounds should be observed, so that it is pointed out that the first step of dehydrochlorination of PVC in the presence of $\mathrm{ZnO}$ proceeds by a mechanism without polyene formation.

\subsection{SEM observation}

The SEM images of dehydrochlorinated product are shown in Fig. 2. As shown in Fig. 2(a), pure PVC used here is particles of 50-150 $\mu \mathrm{m}$ in diameter. In Fig. 2(b) is PVC-ZnO mixed thoroughly in an alumina mortar. PVC particles are covered with a number of small $\mathrm{ZnO}$ particles of $0.1-0.7 \mu \mathrm{m}$. Products obtained after dehydrochlorination and washing are shown in Fig. 2(c). By comparing Figs. 2(a) and (c), it is pointed out that raw PVC particles and dehydrochlorinated PVC show the same shape suggesting that the PVC particles react with $\mathrm{ZnO}$ without melting during the reaction. As described above for results shown in Table 1, dehydrochlorination of PVC in the presence of $\mathrm{ZnO}$ can be regarded as a seemingly solid-solid reaction. It is confirmed from the results obtained here that PVC exists as solid particles during the reaction. Hence it is concluded form the results obtained here that the seemingly solid-solid reaction proceeds because of dissolution of $\mathrm{ZnO}$ in a liquid phase formed during the reaction.

\section{(Insert Fig. 2)}

\subsection{XRD patterns}

The XRD patterns of $\mathrm{PVC}(1.0)-\mathrm{ZnO}(0.75)$ mixture heat-treated at various temperature are shown in Fig. 3 in addition to that of non-treated mixture. Samples were 
heat treated at 453-483 $\mathrm{K}$ for $0.5 \mathrm{~h}$ in nitrogen flow $\left(3.0 \times 10^{-2} \mathrm{dm}^{3} \mathrm{~min}^{-1}\right)$. In the figure, diffraction peaks of non-treated mixture (see pattern (a)) are attributed to those of $\mathrm{ZnO}$ as shown in the figure by $\boldsymbol{\nabla}$. Mixtures treated at $453 \mathrm{~K}$ and $463 \mathrm{~K}$ (see pattern (b) and (c), respectively) give small peaks attributed to zinc(II) oxychloride $\left[\mathrm{Zn}_{2} \mathrm{OCl}_{2} \cdot 2 \mathrm{H}_{2} \mathrm{O}\right.$ ] as shown in the figures by $\mathrm{O}$, in addition to those of $\mathrm{ZnO}$, suggesting that the dehydrochlorination initiates at above $453 \mathrm{~K}$. The mixture treated at $473 \mathrm{~K}$ gives small peaks attributed to simonkolleite $\left.\left[\mathrm{Zn}_{5}(\mathrm{OH})_{8} \mathrm{Cl}_{2} \cdot \mathrm{H}_{2} \mathrm{O}\right]\right]$ as shown in the figure by $\triangle$, in addition to those of zinc(II) oxychloride $(\bigcirc)$ and $\mathrm{ZnO}(\boldsymbol{\nabla})$. As shown as pattern (e), sample heat treated at $483 \mathrm{~K}$ gives strong peaks of zinc(II) oxychloride and weak peaks of $\mathrm{ZnO}$, so that major parts of $\mathrm{ZnO}$ have been consumed for the dehydrochlorination. None of diffraction peak attributed to $\mathrm{ZnCl}_{2}$ was observed. These results shows that the reaction between $\mathrm{ZnO}$ and PVC initiates around $453 \mathrm{~K}$ and proceeds readily above 473 $\mathrm{K}$ in accordance with the results shown in Fig. 1 and Table 1. Crystal formation of Zn-compounds such as simonkolleite and zinc(II) oxychloride was reported [18] for mechano-chemical dechlorination of PVC and poly(vinylidene chloride) in the presence of zinc powder.

\section{(Insert Fig. 3)}

In general, crystal formation requires precipitation of solid phase during condensation of solution, so that formation of simonkolleite and zinc(II) oxychloride observed here give further evidence for appearance of aqueous phase during the reaction. The mechanism of the crystal formation may be considered as illustrated in Fig. 4. Namely, at the initial stage of the reaction (Region A), a small amount of PVC reacts with $\mathrm{ZnO}$ producing an acidic aqueous solution composed of $\mathrm{ZnCl}_{2}$ and water; $\mathrm{ZnO}$ is dissolved in the acidic solution and penetrate into PVC particles and further reaction proceeds between PVC and $\mathrm{ZnO}$ producing further amounts of liquid phase; at the second stage (Region B), production of water reduces and condensation of the acidic solution proceeds followed by crystallization of solute as simonkolleite and/or zinc(II) oxychloride; at the end of reaction (Region C), water is evaporated completely and remains only crystals. Rapid reaction of the seemingly solid-solid reaction and reaction 
of considerable amounts of chlorine atoms in PVC powder (ca. 70\%) is able to explain by applying the mechanism described above, where formation of a liquid-phase acts as reaction promoter.

\section{(Insert Fig. 4)}

\subsection{IR spectra}

Change of IR spectra of pure PVC treated at 473, 573 and $673 \mathrm{~K}$ are given in Fig. 5. In the figure, spectrum (a) is that of untreated PVC. The bands at 2910 and $2970 \mathrm{~cm}^{-1}$ are attributed to C-H stretching vibrations of H-C-H and Cl-C-H, respectively $[19,20]$. Absorption bands at 1340 and $1260 \mathrm{~cm}^{-1}$ are attributed to $\mathrm{H}-\mathrm{C}-\mathrm{Cl}$ deformation vibration, the bands around $1100 \mathrm{~cm}^{-1}$ to C-C stretching vibration, and the bands around 700 and $600 \mathrm{~cm}^{-1}$ to C-Cl stretching vibration. Spectrum (b) is that of pure PVC treated at $473 \mathrm{~K}$. The spectrum is qualitatively identical with that of untreated PVC, so that no detectable reaction proceeds at $473 \mathrm{~K}$. Spectrum (c) and (d) are those of pure PVC treated at 573 and $673 \mathrm{~K}$, respectively. For these spectra, Bands at 1340, 1260 and around 700 and 600 $\mathrm{cm}^{-1}$ disappeared suggesting that major parts of chlorine atom have been removed from PVC as $\mathrm{HCl}$. On the other hand, new absorption bands appear around 3010-3050 which are attributed to $\mathrm{C}-\mathrm{H}$ of polyene or aromatics (expressed as $\mathrm{C}=\mathrm{C}-\mathrm{H}$, hereinafter) and 1600 and $700-900 \mathrm{~cm}^{-1}$ which are attributed to $\mathrm{C}=\mathrm{C}$ double bond and $\mathrm{C}=\mathrm{C}-\mathrm{H}$, respectively. Thus heat treatment of PVC above $573 \mathrm{~K}$ leads to formation of $\mathrm{C}=\mathrm{C}$ double bond. Absorption bands at 2920 and $2850 \mathrm{~cm}^{-1}$ observed in spectrum (c) and (d) are attributed to $\mathrm{C}-\mathrm{H}$ of aliphatic $(\mathrm{CH})_{\mathrm{n}}$ polymer (expressed as $(\mathrm{C})_{3} \mathrm{C}-\mathrm{H}$, hereinafter), because PVC treated above $573 \mathrm{~K}$ is dehydrochlorinated to a considerable extent, and contains only two kinds of hydrogen, $\mathrm{C}=\mathrm{C}-\mathrm{H}$ and $(\mathrm{C})_{3} \mathrm{C}-\mathrm{H}$. Hence absorption bands at 2920 and $2850 \mathrm{~cm}^{-1}$ in spectrum (c) and (d) suggest that PVC heat treated at 573 and $673 \mathrm{~K}$ is abundant in not only $\mathrm{C}=\mathrm{C}-\mathrm{H}$ but also $\mathrm{C}-\mathrm{C}-\mathrm{H}$ structure. It is concluded based on the results described above that dehydrochlorination of pure PVC proceeds above $573 \mathrm{~K}$ and the dehydrochlorinated PVC is abundant in $\mathrm{C}=\mathrm{C}-\mathrm{H}$ and $(\mathrm{C})_{3} \mathrm{C}-\mathrm{H}$ structure.

\section{(Insert Fig. 5)}


IR spectra of PVC-ZnO mixtures treated at $473 \mathrm{~K}$ for $0-5 \mathrm{~h}$ in nitrogen flow are shown in Fig. 6. Absorption bands attributed to C-Cl (2970, 1340, 1260, around 700 and $600 \mathrm{~cm}^{-1}$ ) clearly decrease when heating time is increased from 0.5 to $2 \mathrm{~h}$, and disappears in the spectrum after $5 \mathrm{~h}$ (see spectrum (d)). These results show that, in the presence of $\mathrm{ZnO}$, dehydrochlorination of PVC proceeds easily at $473 \mathrm{~K}$ in accordance with results of thermal dehydrochlorination shown in Table 1. For the spectra of samples heat-treated for 0.5-2 h (spectra (b)-(d)), the bands around 2920 and $2850 \mathrm{~cm}^{-1}$ are attributed to $(\mathrm{C})_{3} \mathrm{C}-\mathrm{H}$ structure and the band at $1100 \mathrm{~cm}^{-1}$ to $\mathrm{C}-\mathrm{C}$ stretching vibration. Since these bands exist even after heat treatment for $5 \mathrm{~h}$ (see spectrum (d)), (C) ${ }_{3} \mathrm{C}-\mathrm{H}$ structure is dominant for dehydrochlorinated PVC produced from PVC-ZnO mixture. On the other hand, for spectrum (b)-(d), there is no appreciable bands of $\mathrm{C}=\mathrm{C}$ double bond at around 3010-3050, 1600 and 700-900 $\mathrm{cm}^{-1}$. These results suggest that $\mathrm{C}=\mathrm{C}$ double bond formation is not the dominant reaction for the reaction of PVC-ZnO mixture at $473 \mathrm{~K}$. It is concluded from the results described above that the low temperature dehydrochlorination of PVC in the presence of $\mathrm{ZnO}$ results in aliphatic $(\mathrm{C})_{3} \mathrm{C}-\mathrm{H}$ structure in preference to $\mathrm{C}=\mathrm{C}-\mathrm{H}$.

\section{(Insert Fig. 6)}

It has been widely accepted that the first step of dehydrochlorination of PVC is polyene formation. However, as described above, the dominant structure of dehydrochlorinated PVC in the presence of $\mathrm{ZnO}$ is not polyene but aliphatic $(\mathrm{CH})_{\mathrm{n}}$. Hence it is difficult to explain the formation of dehydrochlorinated PVC rich in (C) $)_{3} \mathrm{C}-\mathrm{H}$ structure by applying conventional polyene formation mechanism. We propose a new mechanism shown in Fig. 7 for the low-temperature dehydrochlorination. In this mechanism, the main reaction in the presence of $\mathrm{ZnO}$ is a cross-linking $\mathrm{C}-\mathrm{C}$ single bond formation in a polymer chain or among polymer chains followed by formation of aliphatic $(\mathrm{CH})_{\mathrm{n}}$ polymer. The mechanism is reasonably applied to experimental results that dehydrochlorinated PVC is abundant in $(\mathrm{C})_{3} \mathrm{C}-\mathrm{H}$ structure. One of experimental results for the validity of conventional polyene formation mechanism is evolution of organic gases such as benzene during the initial stage of dehydrochlorination. Namely, 
the first step of dehydrochlorination of pure PVC is regarded as polyene formation immediately followed by formation of aromatics due to molecular cyclization (backbiting reaction) and chain-scission [5,6]. However, as reported by Zhang et al. [12] and shown in Table 1, none of organic compounds evolves during the dehydrochlorination in the presence of $\mathrm{ZnO}$. It is difficult to explain the characteristic by applying polyene formation mechanism. On the other hand, the mechanism shown in Fig. 7 suggests that none of organic compounds evolves during the dehydrochlorination because of no chain-scission step being included in the reaction. Hence absence of organic compounds during the dehydrochlorination is also able to explain by applying the mechanism proposed here.

\section{(Insert Fig. 7)}

IR spectra shown in Fig. 8 are those of dehydrochlorinated PVC heat-treated at elevated temperatures for $2 \mathrm{~h}$ in nitrogen flow. Spectrum (a) is that of dehydrochlorinated PVC obtained by heat-treating PVC(1.0)-ZnO(1.0) mixture at 473 $\mathrm{K}$ for $2 \mathrm{~h}$ followed by thoroughly washing to remove Zn-compounds. Adsorption bands of C-Cl (2970, 1340, $1260 \mathrm{~cm}^{-1}$ and around 700 and $600 \mathrm{~cm}^{-1}$ ) are obscure suggesting that the sample have been dehydrochlorinated to a considerable extent. When the sample was heated at 573 and $673 \mathrm{~K}$ (see spectrum (b) and (c), respectively), the bands around 3010-3050 $\mathrm{cm}^{-1}, 1600 \mathrm{~cm}^{-1}$ and $700-900 \mathrm{~cm}^{-1}$ become strong. Since these bands suggest existence of $\mathrm{C}=\mathrm{C}$ double bond structure as described above, the results show that polyene and/or aromatics were formed by heating dehydrochlorinated PVC at higher temperatures than $473 \mathrm{~K}$.

\section{(Insert Fig. 8)}

These results suggest that $(\mathrm{C})_{3} \mathrm{C}-\mathrm{H}$ structure once formed by dehydrochlorination is converted to $\mathrm{C}=\mathrm{C}$ double bond structure as shown in Fig. 9, schematically, where scission of C-C single bond proceeds and gives polyene and/or aromatics. It can be concluded from the results described above that the first step of the dehydrochlorination 
of PVC in the presence of $\mathrm{ZnO}$ is formation of aliphatic $(\mathrm{CH})_{\mathrm{n}}$ due to cross-linking $\mathrm{C}-\mathrm{C}$ single bond formation shown in Fig. 7 and the second step is isomerization of the aliphatic $(\mathrm{CH})_{\mathrm{n}}$ to polyene and/or aromatics as shown in Fig. 9. Since the cross-linking proceeds at a lower temperature $(473 \mathrm{~K})$ than that of the isomerization reaction, it is suggested that the activation energy of the former is lower than that of the latter.

\section{(Insert Fig. 9)}

It has been widely accepted, as described above, that the first step of dehydrochlorination of pure PVC is polyene formation followed by formation of aromatics due to molecular cyclization (backbiting reaction) and chain scission. However, it is difficult to explain by applying the conventional mechanism that dehydrochlorination of pure PVC gives a product rich in $(\mathrm{C})_{3} \mathrm{C}-\mathrm{H}$ structure instead of polyene structure as known from results shown in Fig. 5. In addition, increasing in molecular weight of PVC was often observed [2,5,21-24] during dehydrochlorination even when only a small amount of chlorine (0.3\%) is removed from PVC [23]. This phenomenon implies that cross-linking of polymer chain proceeds to a considerable extent even at the initial stage of dehydrochlorination. When the cross-linking mechanism shown in Fig. 7 is applied to dehydrochlorination of pure PVC, formation of product rich in $(\mathrm{C})_{3} \mathrm{C}-\mathrm{H}$ can be ascribed to formation of aliphatic $(\mathrm{CH})_{\mathrm{n}}$ polymer due to cross-linking dehydrochlorination in a polymer chain or among polymer chains with increasing in molecular weight. Formation of polyene and aromatics can also be ascribed to isomerization of the aliphatic $(\mathrm{CH})_{n}$ shown in Fig. 9 at a higher temperature than that of the cross-linking reaction. It is concluded from the results described above that the cross-linking mechanism shown in Fig. 7 and the isomerization mechanism shown in Fig. 9 can also be applied reasonably to dehydrochlorination of pure PVC.

As described above, dehydrochlorination of PVC-ZnO mixture proceeds at a lower temperature $(473 \mathrm{~K})$ than that of pure PVC. This result suggests that the activation energy of cross-linking dehydrochlorination is lowered in the presence of $\mathrm{ZnO}$. Hendrikse et al. [25,26] reported that $\mathrm{ZnCl}_{2}$ and $\mathrm{Zn}_{2} \mathrm{OCl}_{2}$ act as catalyst for cross-linking reaction of chlorinated poly(isoprene- o-isobutylene) which accompanies 
a new C-C bond formation. Although the compound studied by them is different from PVC, it is implied that zinc-compounds such as $\mathrm{ZnO}, \mathrm{ZnCl}_{2}$ and $\mathrm{Zn}_{2} \mathrm{OCl}_{2}$ are often effective for the cross-linking reaction of chlorinated polymers.

There have been many kinetic studies $[1,4,11,22,24]$ for the dehydrochlorination of pure PVC, and the activation energy of the dehydrochlorination ${ }^{1}$ is $109-134 \mathrm{~kJ} \mathrm{~mol}^{-1}$. Knümann et al. [4] reported that the first step of dehydrochlorination is 3/2-order for concentration of $\mathrm{C}_{2} \mathrm{H}_{3} \mathrm{Cl}$ unit in PVC and the activation energy of the dehydrochlorination is $143.5 \mathrm{~kJ} \mathrm{~mol}^{-1}$. From the reaction order, they were concluded that the reaction proceeds by a radical mechanism. In addition, Liebman et al. [21] reported existence of macroradicals in the early stage of thermal decomposition of PVC under inert atmosphere. By combining these results and those obtained here, it is suggest that the first step of dehydrochlorination of PVC is cross-linking C-C single bond formation shown in Fig. 7 and that the reaction proceeds by a radical mechanism with activation energy around $140 \mathrm{~kJ} \mathrm{~mol}^{-1}$ for pure PVC. In the presence of $\mathrm{ZnO}$, the dehydrochlorination of PVC proceeds very rapidly even at $473 \mathrm{~K}$, thus it is also suggested that the activation energy of the cross-linking dehydrochlorination of PVC is lowered in the presence of $\mathrm{ZnO}$.

\section{Conclusion}

It has been revealed that low temperature dehydrochlorination of PVC in the presence of $\mathrm{ZnO}$ is a seemingly solid-solid reaction but proceeds rapidly due to formation of a liquid-phase as reaction promoter. The dehydrochlorinated PVC is rich in aliphatic $(\mathrm{CH})_{\mathrm{n}}$ and is isomerized to polyene and/or aromatics at a higher temperature. It is suggested that the first step of the dehydrochlorination is not polyene formation but a cross-linking C-C single bond formation in a polymer chain or among different polymer chains. It is also suggested that the thermal dehydrochlorination of pure PVC proceeds by the similar mechanism as the reaction in the presence of $\mathrm{ZnO}$. For the cross-linking reaction, existence of radical species can be assumed. It is pointed out that the dehydrochlorination of PVC in the presence of $\mathrm{ZnO}$ has possibility as a new method for environmentally benign recycling of waste PVC, but further improvement in the efficiency of dehydrochlorination is necessary to apply this reaction to real processes. 


\section{References}

[1] Stromberg, RR, Straus, S, Achhammer, BG. Thermal decomposition of poly(vinyl chloride). J Polym Sci 1959; 35: 355-368.

[2] Lattimer, RP, Kroenke, WJ. The formation of volatile pyrolyzates from poly(vinyl chloride). J Appl Polym Sci 1980; 25: 101-110.

[3] Lattimer, RP, Kroenke, WJ. Mechanisms of formation of volatile aromatic pyrolyzates from poly(vinyl chloride). J Appl Polym Sci 1982; 27: 1355-1366.

[4] Knümann, R, Bockhorn, H. Investigation of the kinetics of pyrolysis of PVC by TG-MS-analysis. Combust Sci Tech 1994; 101: 285-299.

[5] Tüdös, F, Kelen, T, Nagy, TT, Turcsányi, B. Polymer-analogous reactions of polyenes in poly(vinyl chloride). Pure Appl Chem 1974; 38: 201-226.

[6] ÓMara, MM. Combustion of PVC. Pure Appl Chem 1977; 49: 649-660.

[7] McNeill, IC, Memetea, L, Cole, WJ. A study of the products of PVC thermal degradation. Polym Degrad Stab 1995; 49: 181-191.

[8] Uegaki, Y, Nakagawa, Thermal dehydrochlorination of poly(vinyl chloride). I. Effect of iron oxide on the rate of dehydrochlorination. T. J Appl Polym Sci 1977; 21: 965-973.

[9] Ballistreri, A, Foti, S, Maravigna, P, Montaudo, G, Scamporrino, E. Effect of metal oxides on the evolution of aromatic hydrocarbons in the thermal decomposition of PVC. J Polym Sci Polym Chem Ed 1980; 18: 3101-3110.

[10] Montaudo, G, Puglisi, C. Evolution of aromatics in the thermal degradation of poly(vinyl chloride): A mechanistic study. Polym Degrad Stab 1991; 33: 229-262.

[11] Gupta, MC, Viswanath, SG. Role of metal oxides in the thermal degradation of poly(vinyl chloride). Ind Eng Chem Res 1998; 37: 2707-2712.

[12] Zhang, B. Yan, X-Y, Shibata, K, Uda, T, Tada, M, Hirasawa, M. Thermogravimetric-mass spectrometric analysis of the reactions between oxide ( $\mathrm{ZnO}, \mathrm{Fe}_{2} \mathrm{O}_{3}$ or $\mathrm{ZnFe}_{2} \mathrm{O}_{4}$ ). Mater Trans JIM 2000; 41(10): 1342-1350.

[13] Masuda, Y, Uda, T, Terakado, O, Hirasawa, M. Pyrolysis study of poly(vinylchloride)-metal oxide mixtures: Quantitative product analysis and the chloride fixing ability of metal oxides. J Anal Appl Pyrolysis 2006; 77; 159-168.

[14] Lingaiah, N, Uddin, MdA, Muto, A, Sakata, Y, Imai, T, Murata, K. Catalytic dechlorination of chloroorganic compounds from PVC-containing mixed 
plastic-derived oil. Appl Catal A-Gen 2001; 207: 79-84.

[15] Ahmad, Z, Manzoor, W. Thermogravimetric analysis of $\mathrm{ZnCl}_{2}$ catalyzed degradation of PVC. $J$ Therm Anal 1992; 38: 2349-2357.

[16] Owen, ED, Msayib, KJ. Catalyzed degradation of poly(vinylchloride). III. Zinc(II) chloride catalysis. J Polym Sci Pol Chem 1989; 27: 399-408.

[17] Grimes, SM, Lateef, H, Jafari, AJ, Mehta, L. Studies of the effects of copper, copper(II) oxide and copper(II) chloride on the thermal degradation of poly(vinyl chloride). Polym Degrad Stab 2006; 91: 3274-3280.

[18] Xiao, X, Zeng, Z, Xiao, S. Behavior and products of mechano-chemical dechlorination of polyvinyl chloride and poly(vinylidene chloride). J Hazard Mater 2008; 151: 118-124.

[19] Beltrán, M, Marcilla, A. Fourier transform infrared spectroscopy applied to the study of PVC decomposition. Eur Polym J 1997; 33(7): 1135-1142.

[20] Biniak, S. Preparation and characterization of novel IR-transparent semiconducting carbonaceous materials. Carbon 1995; 33(2): 221-224.

[21] Liebman, SA, Reuwer, JF, Jr Gollatz, KA, Nauman, CD. Thermal decomposition of poly(vinyl chloride) and chlorinated poly (vinyl chloride). I. ESR and TGA studies. J Polym Sci Pol Chem 1971; 9: 1823-1833.

[22] Abbås, KB, Sörvik, EM. On the thermal degradation of poly(vinyl chloride) II. The effect of atmosphere. J Appl Polym Sci 1973; 17: 3577-3594.

[23] Abbås, KB, Sörvik, EM. On the thermal degradation of poly(vinyl chloride) III. Structural changes during degradation in nitrogen. J Appl Polym Sci 1975; 19, 2991-3006.

[24] Abbås, KB, Sörvik, EM. On the thermal degradation of poly(vinyl chloride) IV. Initiation sites of dehydrochlorination. J Appl Polym Sci 1976; 20: 2395-2406.

[25] Hendrikse, KG, Mcgill, WJ. Vulcanization of chlorobutyl rubber. II. A revised cationic mechanism of $\mathrm{ZnO} / \mathrm{ZnCl}_{2}$ initiated crosslinking. J Appl Polym Sci 2000; 78: 2302-2310.

[26] Hendrikse, KG, Mcgill, WJ, Reedijk, J, Nieuwenhuizen, PJ. Vulcanization of chlorobutyl rubber. I. The identification of crosslink precursors in compounds containing ZnO/ZnCl 2 . J Appl Polym Sci 2000; 78: 2290-2301. 
Figure captions

Fig. 1. Results of thermal analysis of (a): PVC, (b):PVC-CaO and (c): PVC-ZnO, where (A): TG and (B): DTA in $\mathrm{N}_{2}$ flow.

Fig. 2. SEM images of (a) PVC particles, (b) mixture of PVC-ZnO and (c) PVC dechlorinated in the presence of $\mathrm{ZnO}$ at $473 \mathrm{~K}$ for $0.5 \mathrm{~h}$ in $\mathrm{N}_{2}$ flow.

Fig. 3. XRD patterns of PVC-ZnO mixture (molar ratio 1:0.75) heat treated for $0.5 \mathrm{~h}$ at various temperatures, (a) non-treated, (b) $453 \mathrm{~K}$, (c) $463 \mathrm{~K}$, (d) $473 \mathrm{~K}$, (e) $483 \mathrm{~K}$, (f) $493 \mathrm{~K}$. Symbols represent $\boldsymbol{\nabla}: \mathrm{ZnO}, \triangle$ : simonkolleite, $\bigcirc$ : zinc(II) oxychloride.

Fig. 4. Scheme of reaction between $\mathrm{ZnO}$ and PVC accompanying formation of a liquid phase composed of $\mathrm{ZnO}, \mathrm{ZnCl}_{2}$ and water. In the scheme, (A): region where dehydrochlorination is proceeding with production of a liquid-phase, (B): region where condensation of the liquid-phase and crystallization of Zn-compounds are proceeding and (C): region where liquid-phase disappeared and crystalline of Zn-compounds are existing.

Fig. 5. IR spectra of PVC heat treated at various temperatures for $0.5 \mathrm{~h}$ in $\mathrm{N}_{2}$ flow. Curves are (a) non-treated, (b) $473 \mathrm{~K}$, (c) $573 \mathrm{~K}$, (d) 673K.

Fig. 6. IR spectra of dehydrochlorinated PVC obtained by heat-treating PVC-ZnO at $473 \mathrm{~K}$ for (a) $0 \mathrm{~h}$, (b) $0.5 \mathrm{~h}$, (c) $2.0 \mathrm{~h}$ and (d) $5.0 \mathrm{~h}$.

Fig. 7. Mechanism of cross-linking dehydrochlorination of PVC in the presence of $\mathrm{ZnO}$.

Fig. 8. Change of IR spectrum of (a) dehydrochlorinated PVC, (b) heat-treated at 573 $\mathrm{K}$ and (c) $673 \mathrm{~K}$ for $2 \mathrm{~h}$ in $\mathrm{N}_{2}$ flow.

Fig. 9. Isomerization of dehydrochlorinated PVC produced by cross-linking reaction to olefins and aromatics. 
Table 1. The amount of chlorine as HCl, Zn-salt and included in dehydrochlorinated PVC after the reaction of ZnO-PVC mixture at $473 \mathrm{~K}$ in $\mathrm{N}_{2}$ flow

\begin{tabular}{ccccccc}
\hline \multirow{2}{*}{$\begin{array}{c}\text { Run } \\
\text { No. }\end{array}$} & ZnO-PVC & Reaction Time & \multicolumn{3}{c}{ Cl distribution $/ \%$} & Organic \\
\cline { 4 - 5 } & molar ratio $\left.{ }^{a}\right)$ & /h & HCl & in PVC & Zn-salt & gases b) \\
\hline 1 & $1: 1$ & 2.0 & 0.5 & 30 & 67 & null \\
2 & $3: 1$ & 0.5 & 0.4 & 31 & - & - \\
3 & $3: 1$ & 5.0 & - & 27 & \\
\hline
\end{tabular}

a) The molecule of PVC was regarded formally as $\mathrm{C}_{2} \mathrm{H}_{3} \mathrm{Cl}$ for the calculation of molar ratio.

b) Results obtained separately by temperature programmed decomposition. 
Fig. 1
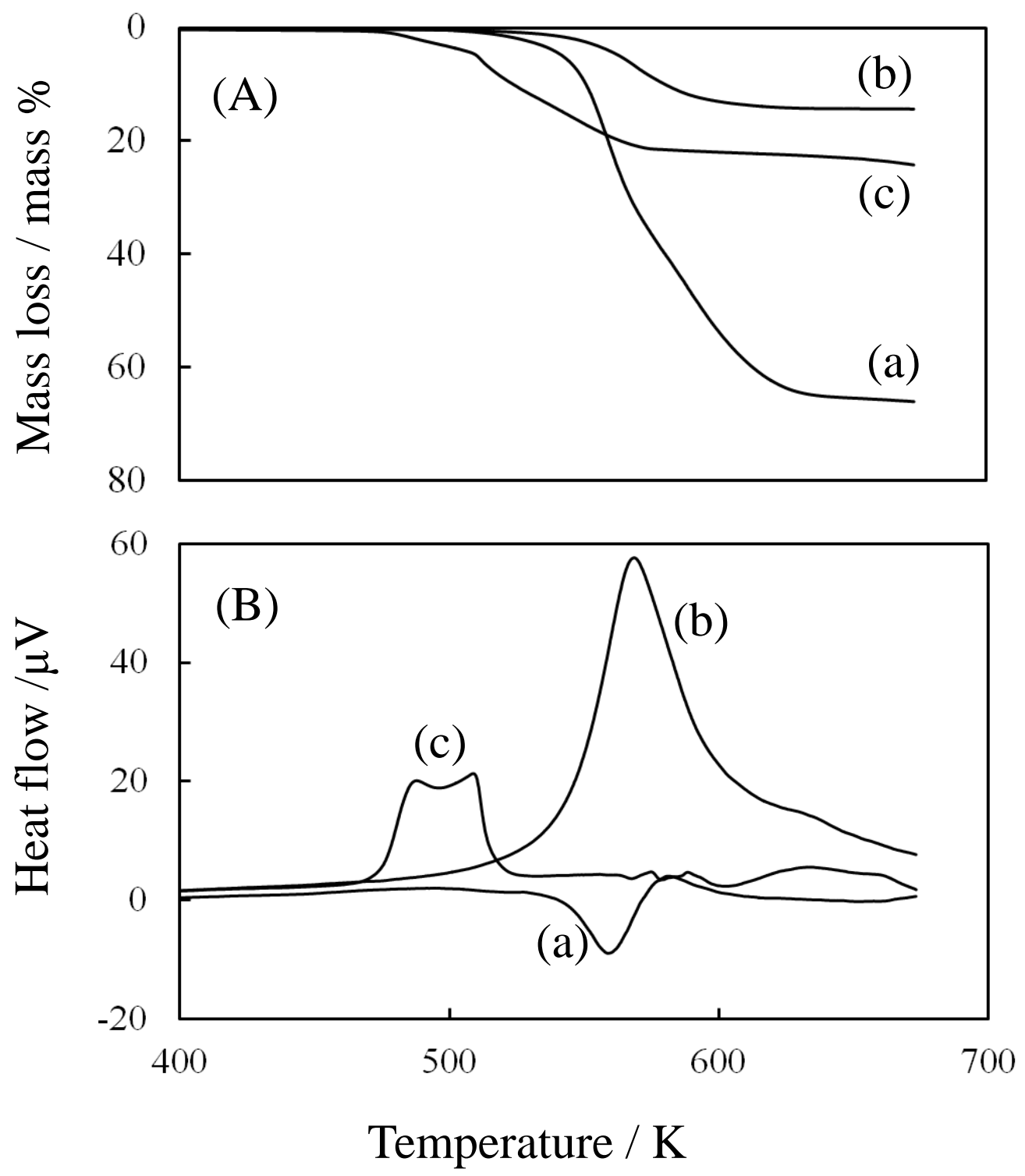
Fig. 2

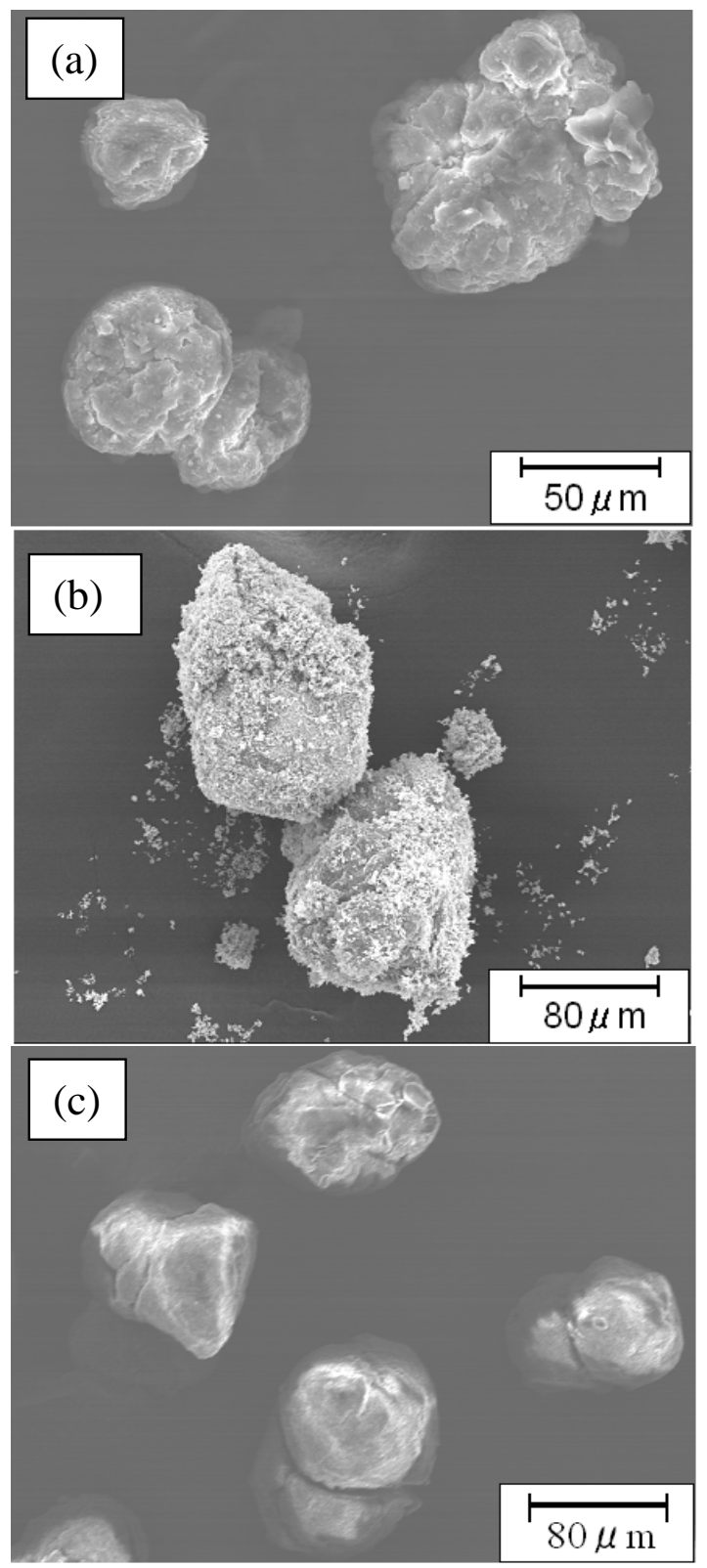


Fig. 3

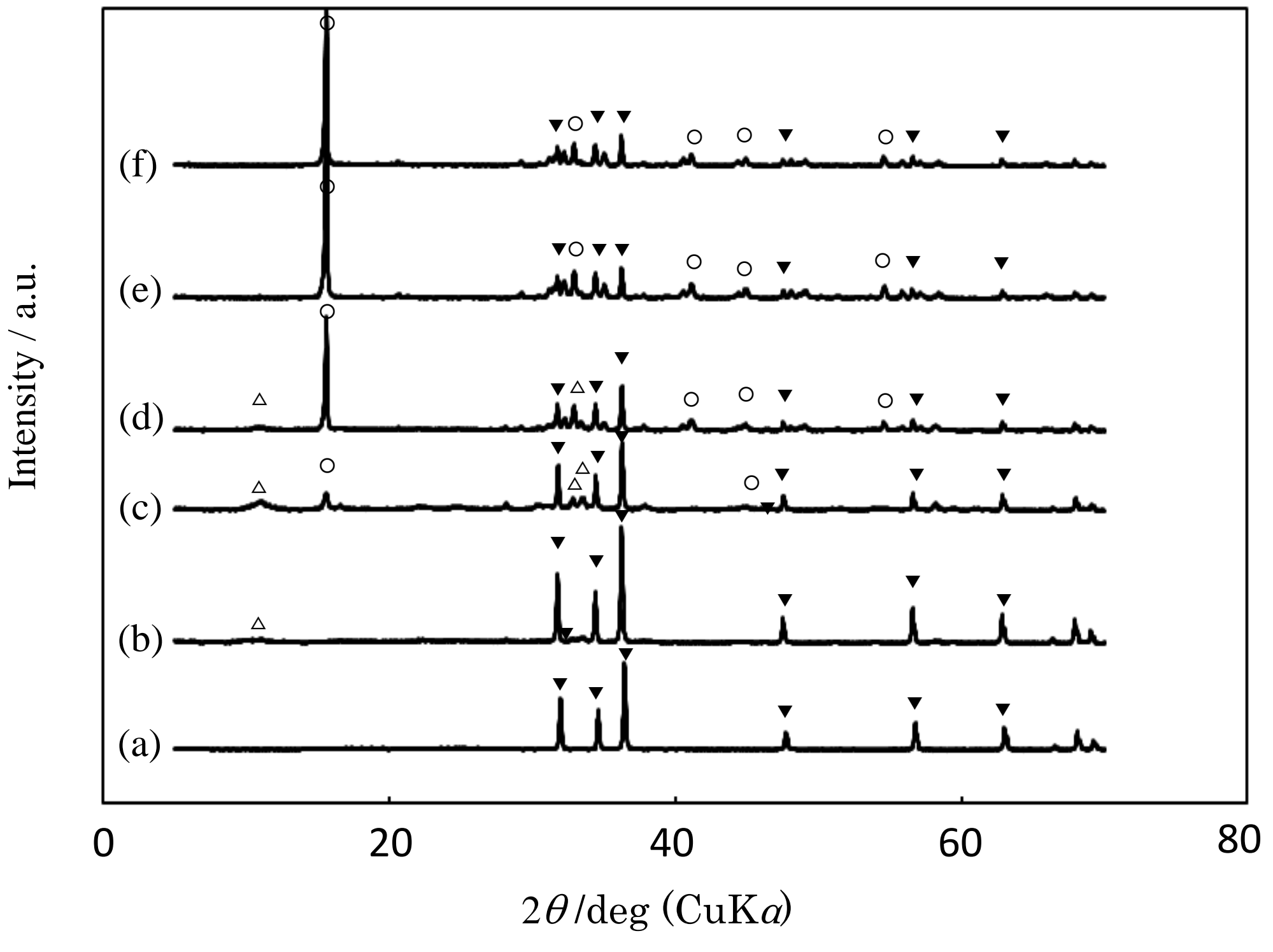


Fig. 4
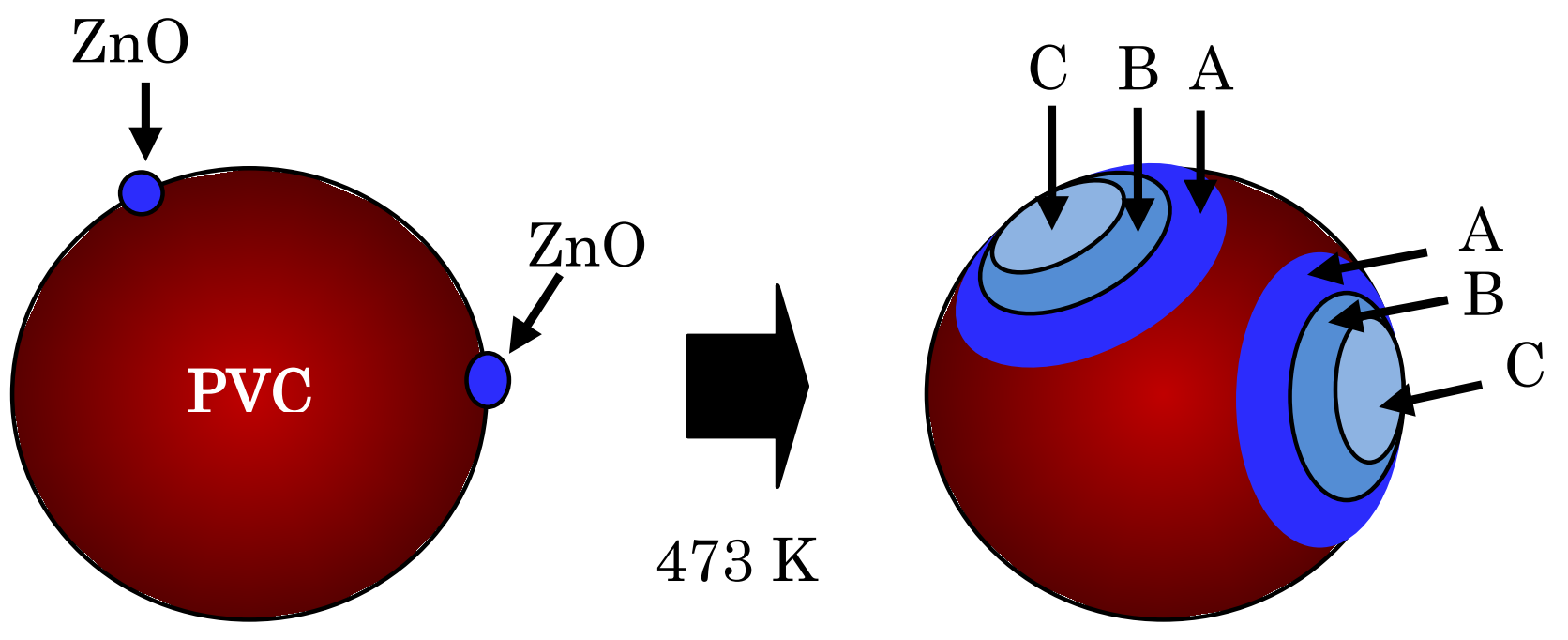
Fig. 5
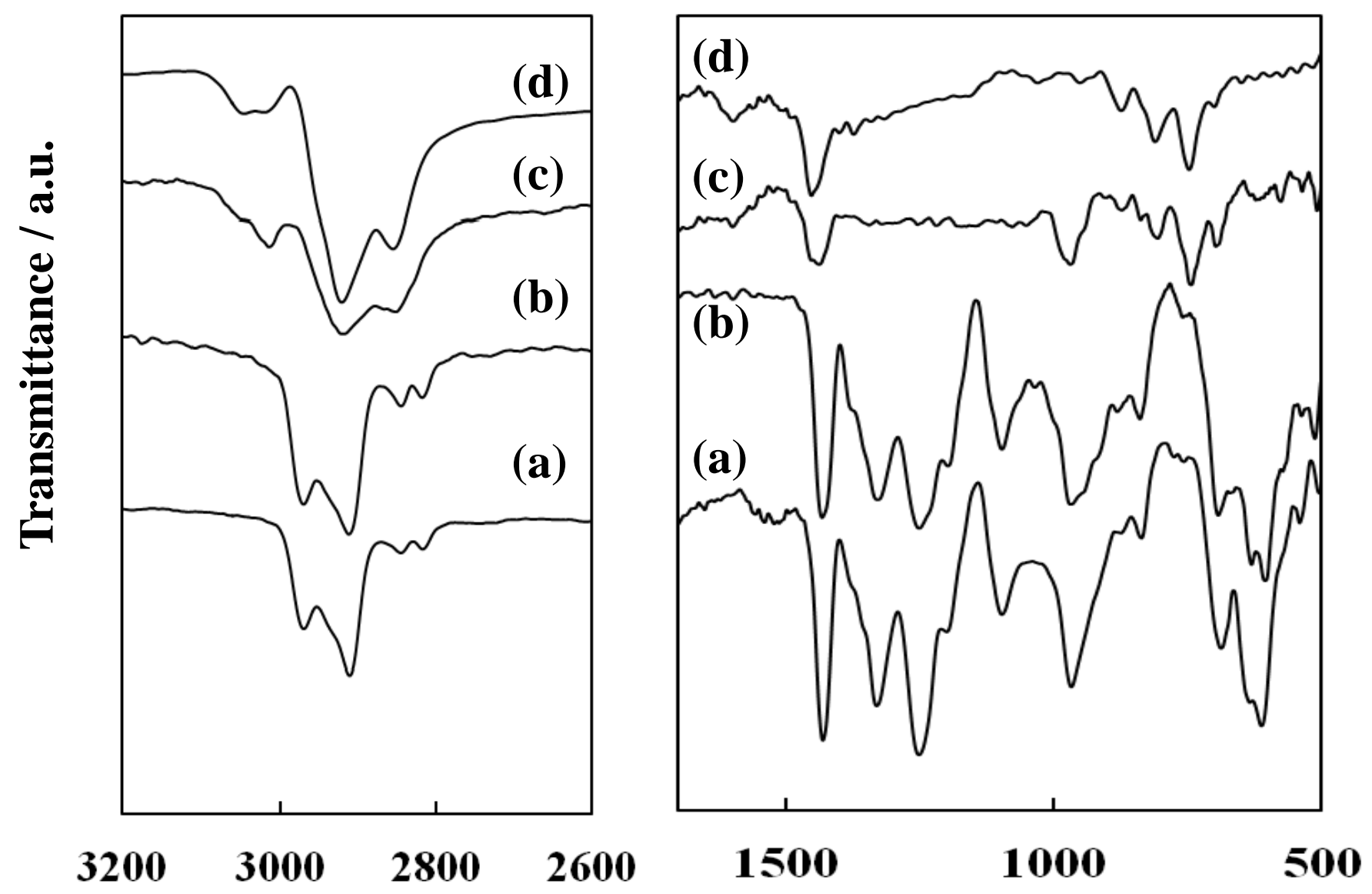

Wavenumber / $\mathrm{cm}^{-1}$ 
Fig. 6

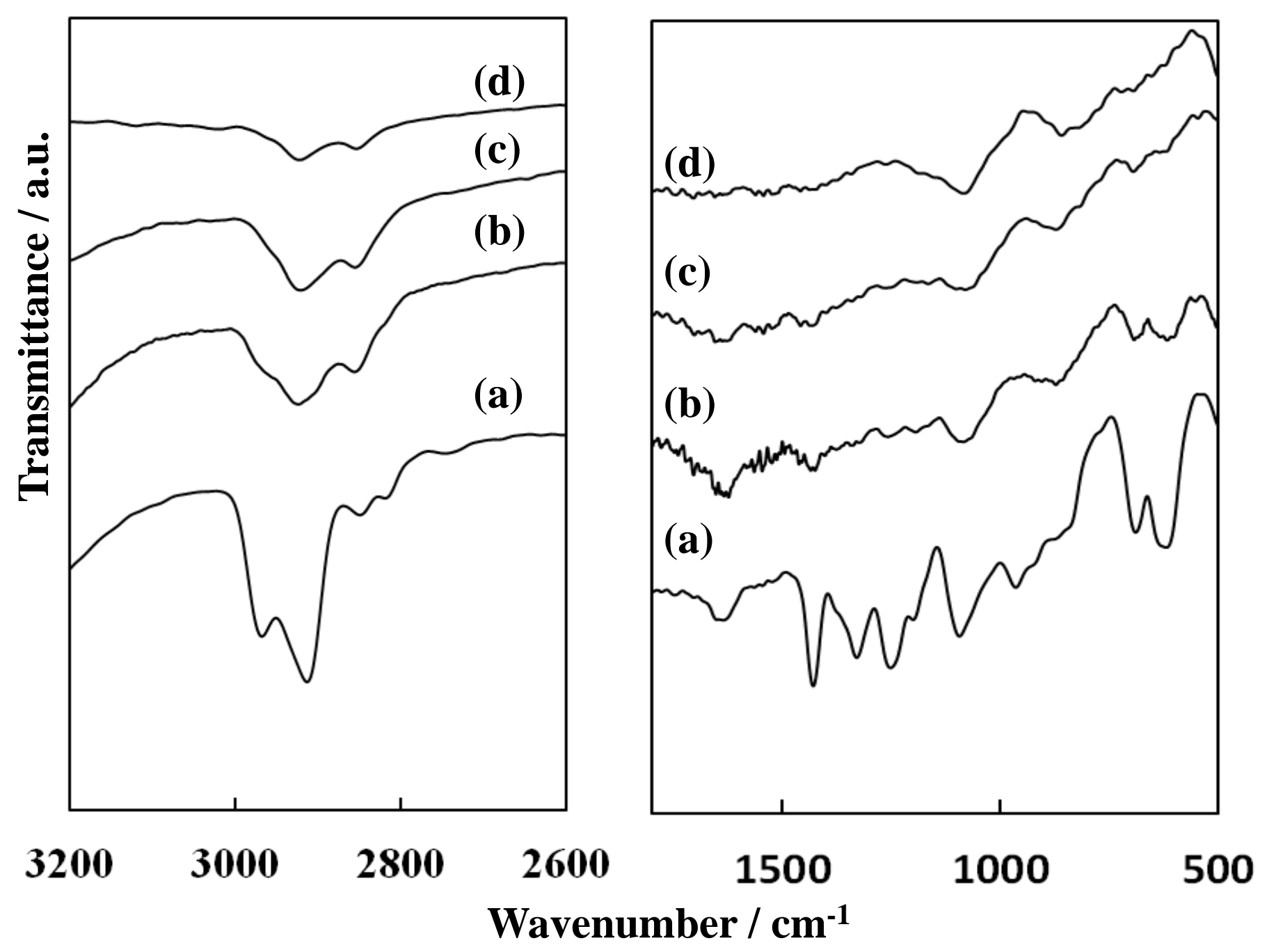


Fig. 7
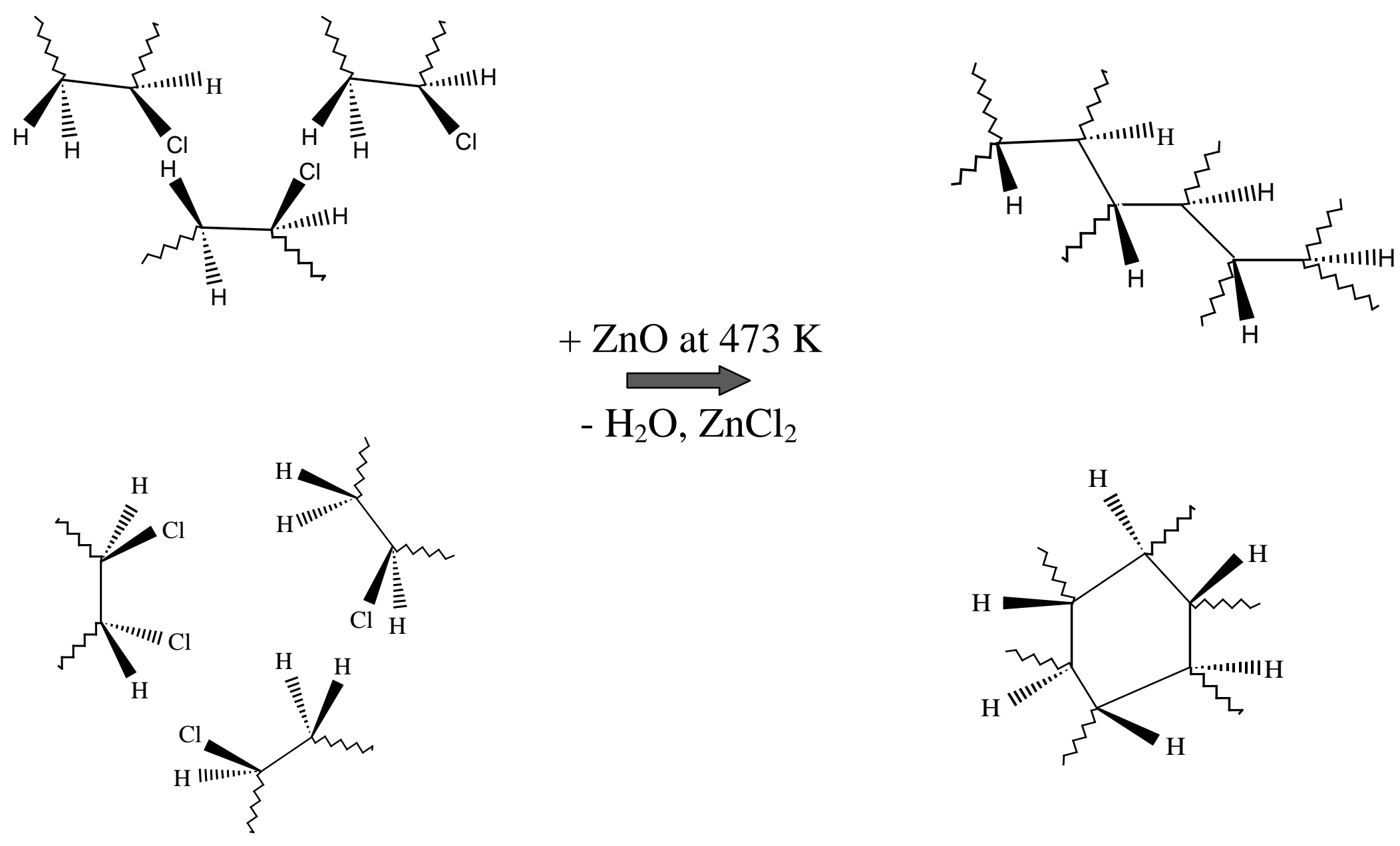
$+\mathrm{ZnO}$ at $473 \mathrm{~K}$
- $\mathrm{H}_{2} \mathrm{O}, \mathrm{ZnCl}_{2}$

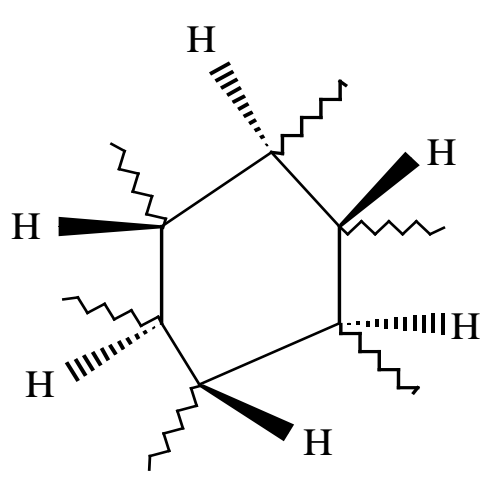


Fig. 8
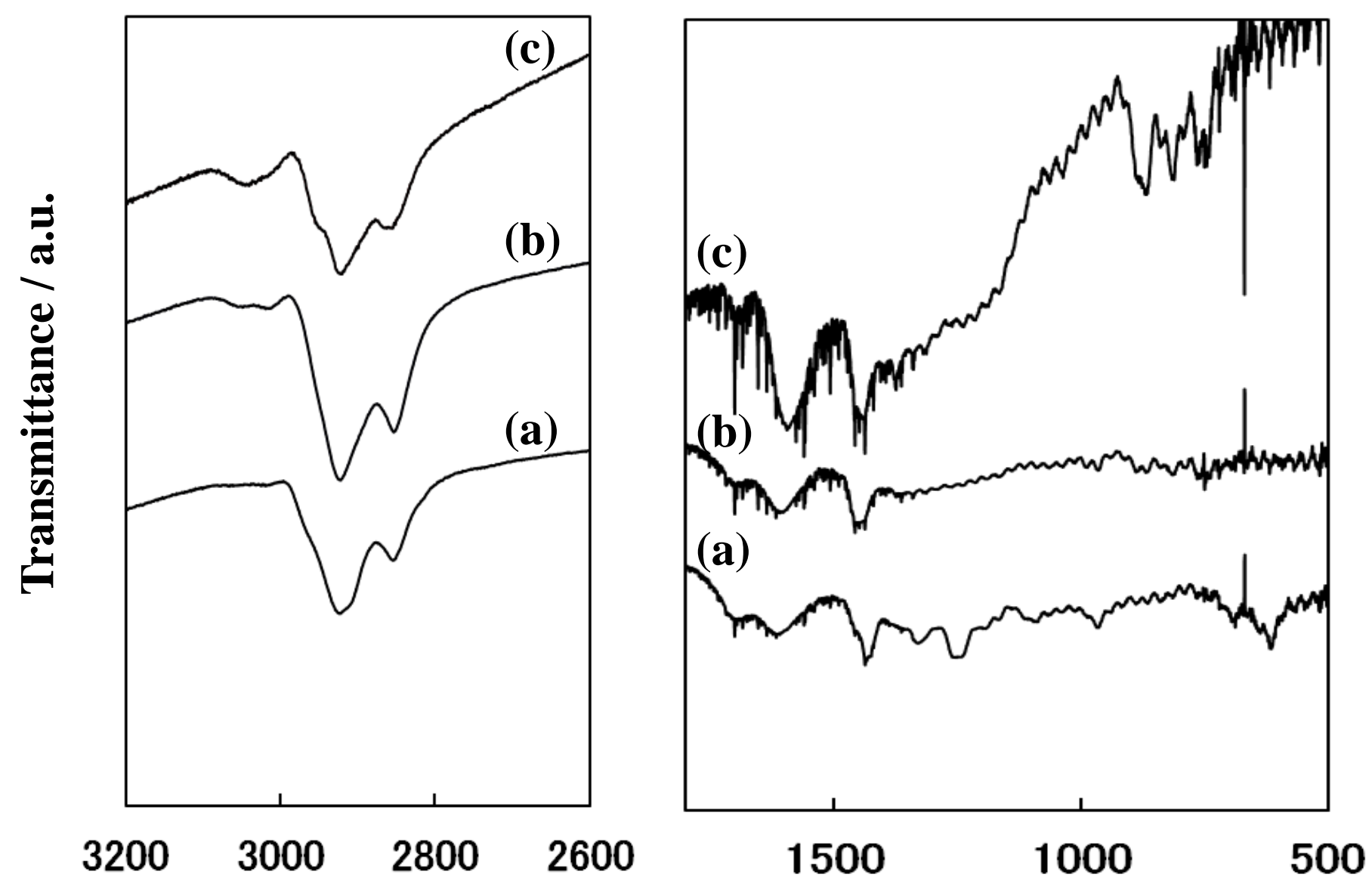

Wavenumber / $\mathrm{cm}^{-1}$ 
Fig. 9
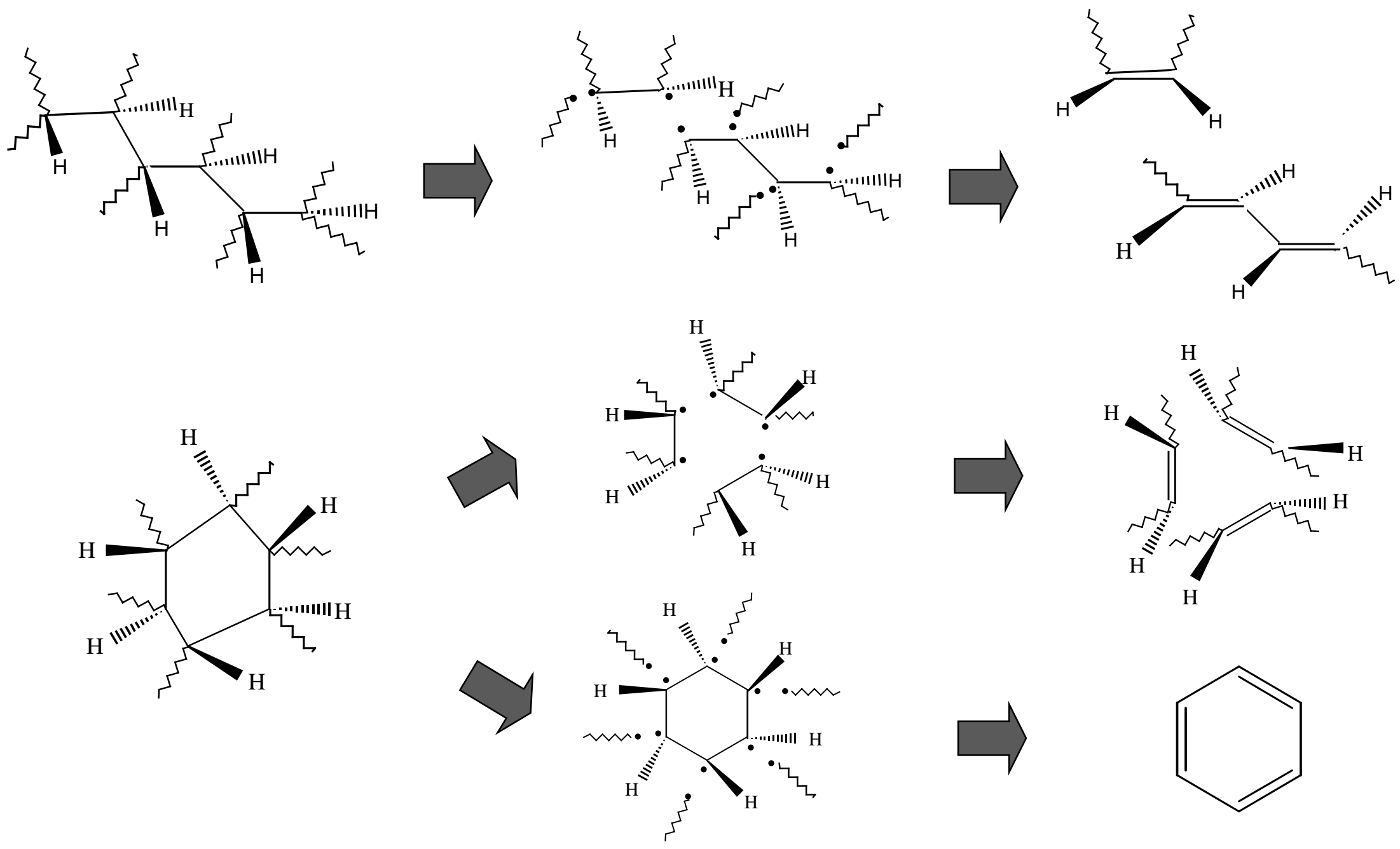